TITLE:

\title{
Kinetic analysis for the isomerization of glucose, fructose, and mannose in subcritical aqueous ethanol.
}

\author{
AUTHOR(S):
}

Gao, Da-Ming; Kobayashi, Takashi; Adachi, Shuji

\section{CITATION:}

Gao, Da-Ming ...[et al]. Kinetic analysis for the isomerization of glucose, fructose, and mannose in subcritical aqueous ethanol.. Bioscience, biotechnology, and biochemistry 2015, 79(6): 1005-1010

\section{ISSUE DATE:}

2015

URL:

http://hdl.handle.net/2433/202261

\section{RIGHT:}

This is an Accepted Manuscript of an article published by Taylor \& Francis in 'Bioscience, Biotechnology, and Biochemistry' on 2015, available online: http:/ www tandfonline.com/10.1080/09168451.2014.1003129. The full-text file will be made open to the public on 22 Jan 2016 in accordance with publisher's 'Terms and Conditions for SelfArchiving'.; This is not the published version. Please cite only the published version.; この論文は出版社版でありません 。引用の際には出版社版をご確認ざ利用ください。 
Running title: Isomerization of hexoses promoted by ethanol

Kinetic analysis for the isomerization of glucose, fructose, and mannose in subcritical aqueous ethanol

Da-Ming Gao, Takashi Kobayashi and Shuji Adachi ${ }^{*}$

Division of Food Science and Biotechnology, Graduate School of Agriculture, Kyoto University, Sakyo-ku, Kyoto 606-8502, Japan.

Received November 6, 2014; Accepted December 17, 2014

*Corresponding author: Tel.: +81-75-753-6286; Fax: +81-75-753-6285;

*E-mail: adachi@kais.kyoto-u.ac.jp 


\section{Abstract:}

2 Fructose, glucose, and mannose were treated with subcritical aqueous ethanol for

3 ethanol concentrations ranging from 0 to $80 \%(\mathrm{v} / \mathrm{v})$ at $180-200{ }^{\circ} \mathrm{C}$. The aldose-ketose

4 isomerization was more favorable than ketose-aldose isomerization and

5 glucose-mannose epimerization. The isomerization of the monosaccharides was

6 promoted by the addition of ethanol. In particular, mannose was isomerized most easily

7 to fructose in subcritical aqueous ethanol. The apparent equilibrium constants for the

8 isomerizations of mannose to fructose, $K_{\text {eq, } M \rightarrow F}$, and glucose to fructose, $K_{\text {eq, G } \rightarrow \mathrm{F}}$, were

9 independent of ethanol concentration and increased with increasing temperature.

10 Moreover, the $K_{\mathrm{eq}, \mathrm{M} \rightarrow \mathrm{F}}$ value was much larger than the $K_{\mathrm{eq}, \mathrm{G} \rightarrow \mathrm{F}}$ value. The enthalpies for

11 the isomerization of mannose to fructose, $\Delta H_{\mathrm{M} \rightarrow \mathrm{F}}$, and glucose to fructose, $\Delta H_{\mathrm{G} \rightarrow \mathrm{F}}$, were estimated to be 18 and $24 \mathrm{~kJ} / \mathrm{mol}$, respectively, according to van't Hoff equation.

13 Subcritical aqueous ethanol can be used to produce fructose from glucose and mannose

14 efficiently.

16 Keywords: fructose; glucose; isomerization; mannose; subcritical aqueous ethanol 


\section{Introduction}

Fructose is a common reducing ketose that is used commercially as a sweetener in beverages to enhance our enjoyment of foods. Fructose has positive health effects in humans as it enhances glucocorticoid action ${ }^{1)}$ and insulin resistance. ${ }^{2)}$ Recently, fructose has been used as a renewable resource to synthesize biofuels and biochemical ${ }^{3,4)}$ such as role in food and related industries. alkalis, metals, and enzymes. The alkali-catalyzed isomerization has been well known as the Lobry de Bruyn-Alberda van Ekenstein transformation (LBAE transformation). In the LBAE transformation, fructose is produced from glucose in high yield (ca. $38 \%$ at $25{ }^{\circ} \mathrm{C}$ ) and from mannose in relatively low yield (ca. $25 \%$ at $\left.25{ }^{\circ} \mathrm{C}\right) .{ }^{5)}$ However, alkali-catalyzed isomerization usually results in many by-products, thus restricting its application. The product distribution in metal-catalyzed isomerization depends on the

31 type of metal ion, saccharides, cosolvents, and metal ion carrier. ${ }^{6-8)}$ Metal-catalyzed isomerization cannot meet commercial demands because of the low feed concentration of the substrates or the difficulty in synthesizing the catalysts. The current industrial isomerization process to produce fructose involves the utilization of an immobilized 
glucose isomerase. This enzymatic isomerization is reversible (the equilibrium constant,

$K_{\text {eq }}$, is $c a .1$ at $25^{\circ} \mathrm{C}$ ) and slightly endothermic, indicating that the maximum attainable yield of fructose is governed by the reaction temperature. ${ }^{8)}$

Many researchers have investigated the isomerization of saccharides such as glucose, mannose, and fructose in $100 \%(\mathrm{v} / \mathrm{v})$ subcritical water. ${ }^{9-11)}$ It was reported that aldoses isomerized easily than ketoses in $100 \%(\mathrm{v} / \mathrm{v})$ subcritical water. ${ }^{10)}$ Although kinetic analysis revealed that mannose was isomerized most easily to fructose among glucose, mannose, and fructose, the yields of fructose and glucose from mannose were still low. It was also reported that increasing the temperature shifted the chemical equilibrium constant for the isomerization of aldoses to ketoses to a higher value. ${ }^{10)}$ chemical equilibrium. Ethanol has been widely investigated in the isomerization of aldoses at ambient temperature using bases, enzymes, or metals. ${ }^{12-14)}$ Adding ethanol to the solvent significantly promoted these isomerizations. The promoting effect of ethanol at low temperatures is usually attributed to changes in both the conformation and

50 configuration of saccharides in aqueous ethanol ${ }^{15)}$ and the change in the apparent 51 chemical equilibrium. ${ }^{7)}$ 
53 addition of ethanol under subcritical conditions. ${ }^{16)}$ The yield of fructose was lower than

54 that of glucose, and this difference increased with increasing ethanol concentration,

55 possibly because of the isomerization between the two saccharides. ${ }^{16)}$ However, the

56 mechanism of isomerization has not been clarified. Therefore, we analyzed the kinetics

57 of the isomerization of glucose, mannose, and fructose in subcritical aqueous ethanol.

Materials and Methods

60

Materials. Ethanol (purity, $99.5 \%$ ), D-fructose (> $99 \%$ ), and D-glucose (>99\%) were

61 purchased from Wako Pure Chemical Industries (Osaka, Japan). D-Mannose (> 99 \%) was purchased from Nacalai Tesque (Kyoto, Japan).

63

Isomerization among fructose, glucose, and mannose in subcritical aqueous ethanol.

Each monosaccharide was dissolved in distilled water, and ethanol was added to produce the substrate solution with a final saccharide concentration of $0.5 \%(\mathrm{w} / \mathrm{v})$, at which it was possible to detect saccharides and derivatives using an RI detector. In

68 addition, this concentration would not be greatly deviated from the ideal solution. The solution was sonically degassed under reduced pressure before the subcritical treatment.

The solution reservoir was connected to a helium gasbag to prevent the redissolution of 
oxygen, because saccharides may be oxidized into side products, which is not expected

72 for the isomerization process. ${ }^{17)}$ The solution was delivered into a coiled stainless steel

73 tubular reactor $(0.8 \mathrm{~mm}$ I.D. $\times 1.0 \mathrm{~m}$ length $)$ immersed in an SRX 310 silicone oil bath

74 (Toray-Dow-Corning Silicone, Tokyo, Japan) with the residence time of 30-500 s using an LC-10AD VP HPLC pump (Shimadzu, Kyoto, Japan). The reaction temperature was in the range $180-200{ }^{\circ} \mathrm{C}$. To rapidly terminate the reaction, the reactor effluent was directly introduced to a stainless steel tube immersed in an ice bath. The pressure inside the tube was regulated at $c a .10 \mathrm{MPa}$ using a back-pressure valve (Upchurch Scientific Inc., Oak Harbor, WA, USA). Finally, the effluent was collected into a test tube for the HPLC analysis.

HPLC analysis. The concentrations of unreacted substrate and produced monosaccharides were quantified using an HPLC system equipped with an LC-10ADVP HPLC pump (Shimadzu), an RI-101 refractometer (Showa Denko, Tokyo,

86 Japan), and a SUPELCOGEL $\mathrm{Ca}^{2+}$ column $(7.8 \mathrm{~mm}$ I.D. $\times 300 \mathrm{~mm}$ length, Sigma-Aldrich, Tokyo, Japan) equipped with a guard column (4.6 mm I.D. $\times 50 \mathrm{~mm}$ 
$890.25 \mathrm{~mL} / \mathrm{min}$. The columns were maintained at $30{ }^{\circ} \mathrm{C}$ in a CTO-10AVP column oven

90 (Shimadzu). 


\section{$91 \quad$ Results and discussion}

92

Effect of ethanol concentration on glucose isomerization

94 Figure 1 shows the effect of ethanol concentration on glucose isomerization at $180^{\circ} \mathrm{C}$.

95 When the ethanol concentration exceeded $40 \%(\mathrm{v} / \mathrm{v})$, glucose isomerization significantly increased with increasing ethanol concentration. Fructose and mannose

97 were competitively produced from glucose both in subcritical water and in subcritical

98 aqueous ethanol. The yield of fructose was almost seven-fold higher than that of mannose at $500 \mathrm{~s}$ in $60 \%(\mathrm{v} / \mathrm{v})$ aqueous ethanol. Mannose was not detected when the

100 ethanol concentration was below $40 \%(\mathrm{v} / \mathrm{v})$. These results were in contrast to those of

101 the hydrolysis of sucrose in subcritical aqueous ethanol. The hydrolysis of sucrose

102 decreased with increasing ethanol concentration, and the isomer of sucrose was not

103 obtained. ${ }^{16)}$ This indicates that only the isomerization of reducing sugars is promoted in 104 subcritical aqueous ethanol.

105 Figure 1 also shows that ethanol affected the isomerization and decomposition 106 behaviors of glucose. The yield of fructose increased with increasing ethanol concentration at $500 \mathrm{~s}$ (Fig. 2). The selectivity of fructose also increased by the addition

108 of ethanol and reached the highest value in $60 \%(\mathrm{v} / \mathrm{v})$ aqueous ethanol, where the 
109 selectivity was defined as the molar ratio of the produced monosaccharide to the

110 consumed substrate. Although the selectivity of mannose was lower than that of fructose,

111 it reached ca. 0.1 when the ethanol concentration was $>60 \%(\mathrm{v} / \mathrm{v})$. The total saccharide

112 concentration was maintained at a high level, which was slightly lower than the feed

113 glucose concentration and scarcely depended on the ethanol concentration at $180{ }^{\circ} \mathrm{C}$,

114 regardless of the increase in the conversion of glucose. This indicates that the side

115 reaction of glucose was not significantly accelerated, and that most of the consumed

116 glucose was converted to fructose and mannose in subcritical aqueous ethanol at

$117 \quad 180{ }^{\circ} \mathrm{C}$.

118 The contribution of ethanol in promoting glucose isomerization under subcritical

119 aqueous conditions is still unclear. It is known that the $\mathrm{p} K_{\mathrm{a}}$ values of glucose in aqueous

120 ethanol and methanol- $d_{4}$ decrease with increasing alcohol concentration at ambient

121 temperature, and that the initial reaction rate of alkali-catalyzed glucose isomerization is

122 positively related to the ionization constant. ${ }^{12)}$ Therefore, an increase in ethanol concentration would accelerate glucose isomerization. Another important role of ethanol

124 is that it changes the anomeric equilibrium of glucose, thus changing the apparent

125 chemical equilibrium and facilitating the isomerization of glucose. ${ }^{15)}$ Ethanol not only 
127 atom migration during the isomerization. ${ }^{6)}$ On the other hand, a recent study reported

128 that the initial presence of water in aqueous alcohol suppressed the

129 aluminum-containing zeolite-catalyzed isomerization of glucose to fructose at $120{ }^{\circ} \mathrm{C}$,

130 and that the one-pot synthesis of fructose from glucose could not be performed using

131 aqueous alcohol. ${ }^{18)}$ However, these reported results are different from our results. One

132 of the reasons may be that the reaction temperature was different in our study, and the

133 role of ethanol in promoting glucose isomerization may change under subcritical

134 conditions.

$136 \quad$ Temperature dependence of glucose isomerization

137 Figure 3 shows the effect of temperature on glucose isomerization in $80 \%(\mathrm{v} / \mathrm{v})$

138 subcritical aqueous ethanol. Increasing reaction temperature increased the conversion of

139 glucose and the yields of fructose and mannose at a given residence time. The

140 maximum yield of fructose was achieved faster at higher temperatures. However, the

141 total saccharide concentration at a given residence time decreased with increasing

142 reaction temperature (Fig. 2), indicating that the fraction of disappeared hexoses

143 increased at higher temperatures. Another disadvantage of increasing the reaction

144 temperature is that the selectivity of fructose decreased. A higher maximum yield of 
145 fructose was realized at higher temperatures even though the selectivity was lower. In

146 contrast, the selectivity increased at lower temperatures even though a longer residence

147 time was required. Therefore, an appropriate temperature should be selected for the

148 efficient production of fructose from glucose. Similar temperature effects were also

149 observed at other ethanol concentrations. To achieve the maximum yield of fructose

150 within a short time, the isomerization was performed in $80 \%(\mathrm{v} / \mathrm{v})$ aqueous ethanol at

$151 \quad 180{ }^{\circ} \mathrm{C}$ in the subsequent studies.

154 To investigate the mutual isomerization among glucose, mannose, and fructose, the

155 latter two saccharides were also treated under the same conditions as those for glucose.

156 Fig. 4 shows the isomerizations of fructose to glucose and mannose, glucose to fructose

157 and mannose, and mannose to fructose and glucose in $80 \%(\mathrm{v} / \mathrm{v})$ aqueous ethanol at

$158180{ }^{\circ} \mathrm{C}$. The consumption of fructose was the slowest among the three saccharides.

159 Although mannose and glucose were produced from fructose almost in the same yields,

160 the yields were low. These results indicated that fructose significantly decomposed

161 under these conditions.

162 The isomerization of mannose proceeded faster than that of fructose and glucose. 
163 Fructose was most produced from mannose. However, when mannose was treated with

$16480 \%(\mathrm{v} / \mathrm{v})$ aqueous ethanol at $200{ }^{\circ} \mathrm{C}$, the yield of fructose first reached the highest

165 value at a residence time of $c a .150 \mathrm{~s}$ and then decreased at longer residence times,

166 indicating that the fructose obtained was consequently decomposed (Fig. 4(b)). The

167 yield of fructose produced from mannose was higher than that of fructose produced

168 from glucose within the investigated residence time. Glucose was produced from

169 mannose in a relatively low yield; however, the yield was more than that of mannose

170 produced from glucose.

171 The substrate-dependent chemoselective isomerization of the investigated monosaccharides in subcritical aqueous ethanol was unique compared to the alkali- and

173 metal-catalyzed isomerizations. ${ }^{5-7)}$ In alkaline aqueous solutions, fructose isomerized to glucose with the highest rate and excellent selectivity. However, the isomerization of mannose was the slowest, and both glucose and fructose were produced almost in the same yield. ${ }^{5)}$ Moreover, mannose isomerized slower than glucose in many ethanolic and

177 methanolic solutions of metal ions. ${ }^{6,7)}$ Many studies reported that glucose was

178 isomerized to fructose more easily than mannose under alkaline conditions. ${ }^{15,19,20)}$ These studies were carried out at low reaction temperatures. The unique product distribution among the investigated saccharides in subcritical aqueous ethanol can be attributed to 
181 the difference in the temperature dependence of the rate constants of the reactions.

As shown above, glucose, mannose, and fructose were isomerized and decomposed the reaction rate of each monosaccharide can be expressed as follows:

$$
\frac{d C_{\mathrm{F}}}{d t}=-\left(k_{\mathrm{F} \rightarrow \mathrm{G}}+k_{\mathrm{F} \rightarrow \mathrm{M}}+k_{\mathrm{Fd}}\right) C_{\mathrm{F}}+k_{\mathrm{G} \rightarrow \mathrm{F}} C_{\mathrm{G}}+k_{\mathrm{M} \rightarrow \mathrm{F}} C_{\mathrm{M}}
$$

$$
\frac{d C_{\mathrm{G}}}{d t}=-\left(k_{\mathrm{G} \rightarrow \mathrm{F}}+k_{\mathrm{G} \rightarrow \mathrm{M}}+k_{\mathrm{Gd}}\right) C_{\mathrm{G}}+k_{\mathrm{F} \rightarrow \mathrm{G}} C_{\mathrm{F}}+k_{\mathrm{M} \rightarrow \mathrm{G}} C_{\mathrm{M}}
$$

$$
\frac{d C_{\mathrm{M}}}{d t}=-\left(k_{\mathrm{M} \rightarrow \mathrm{G}}+k_{\mathrm{M} \rightarrow \mathrm{F}}+k_{\mathrm{Md}}\right) C_{\mathrm{M}}+k_{\mathrm{F} \rightarrow \mathrm{M}} C_{\mathrm{F}}+k_{\mathrm{G} \rightarrow \mathrm{M}} C_{\mathrm{G}}
$$

where $C_{\mathrm{F}}, C_{\mathrm{G}}$, and $C_{\mathrm{M}}$ are the concentrations of fructose, glucose, and mannose,

respectively. the sum of the residual square between the experimental and calculated $C_{i}$ values using the Solver of Microsoft ${ }^{\circledR}$ Excel 2010. The curves in Figs. 1, 3, and 4 were drawn using the estimated rate constants. The rate constants obtained for the isomerization and 
199 decomposition of each substrate at 180 , 190, and $200{ }^{\circ} \mathrm{C}$ were plotted against the

200 ethanol concentrations shown in Fig. 5. The values of $k_{\mathrm{M} \rightarrow \mathrm{F}}, k_{\mathrm{G} \rightarrow \mathrm{F}}$, and $k_{\mathrm{Fd}}$ were larger

201 than the others under any condition, and the $k_{\mathrm{M} \rightarrow \mathrm{F}}$ value was the largest, indicating that

202 mannose was most easily isomerized to fructose. In contrast, the rate constants for the

203 reverse reactions, $k_{\mathrm{F} \rightarrow \mathrm{M}}$ and $k_{\mathrm{F} \rightarrow \mathrm{G}}$, were much smaller. The rate constants for the

204 isomerizations between mannose and glucose, $k_{\mathrm{M} \rightarrow \mathrm{G}}$ and $k_{\mathrm{G} \rightarrow \mathrm{M}}$, were also smaller than

$205 k_{\mathrm{M} \rightarrow \mathrm{F}}$ and $k_{\mathrm{G} \rightarrow \mathrm{F}}$. These results indicated that the isomerization of mannose and glucose to

206 fructose was faster than the reverse reactions and the isomerization between mannose

207 and glucose, and that these isomerizations were accelerated by the addition of ethanol

208 and increase in temperature. Although decompositions were also promoted by increase

209 in temperature and ethanol concentration, they were less sensitive to temperature and

210 ethanol concentration than isomerizations. The $k_{\mathrm{M} \rightarrow \mathrm{F}}$ was the most sensitive to the

211 change in ethanol concentration.

212 To investigate the temperature dependence of the rate constants, the $k_{i}$ values were

213 plotted against the reciprocal of absolute temperature (Arrhenius plot). Fig. 6 shows the

214 typical Arrhenius plots of the rate constants obtained in $80 \%(\mathrm{v} / \mathrm{v})$ subcritical aqueous

215 ethanol. The rate constants of the respective reaction steps separately lie on the straight

216 lines. The frequency factors and activation energies were calculated to be in the ranges 
217 of $10^{8}-10^{12} \mathrm{~s}^{-1}$ and $90-130 \mathrm{~kJ} / \mathrm{mol}$, respectively. The activation energies of the

218 isomerizations were similar to those of the monosaccharide decompositions in $100 \%$

$219(\mathrm{v} / \mathrm{v})$ subcritical water, ${ }^{21)}$ thus indicating that the isomerization and decomposition of

220 monosaccharides would have a similar energy barrier.

221

222

Reaction equilibrium for the isomerization of monosaccharides

223

Figure 5 also shows that the isomerizations of mannose to fructose and glucose to

224 fructose have high reaction equilibrium constants, $K_{\text {eq }}$. The $K_{\text {eq }}$ values were calculated

225 from the rate constants $\left(K_{\mathrm{eq}, \mathrm{M} \rightarrow \mathrm{F}}=k_{\mathrm{M} \rightarrow \mathrm{F}} / k_{\mathrm{F} \rightarrow \mathrm{M}}\right.$ and $\left.K_{\mathrm{eq}, \mathrm{G} \rightarrow \mathrm{F}}=k_{\mathrm{G} \rightarrow \mathrm{F}} / k_{\mathrm{F} \rightarrow \mathrm{G}}\right)$; they were not

affected by ethanol concentration. The equilibrium constants for each reaction at

different ethanol concentrations were averaged and plotted against the reciprocals of

absolute temperature according to van't Hoff equation:

229

$$
\ln K_{\mathrm{eq}}=-\frac{\Delta H}{R T}
$$

where $\Delta H$ and $R$ are the change in enthalpy and gas constant, respectively (Fig. 7). The equilibrium constants for the isomerization of mannose to fructose, $K_{\mathrm{eq}, \mathrm{M} \rightarrow \mathrm{F}}$, were

higher than those for the isomerization of glucose to fructose, $K_{\mathrm{eq}, \mathrm{G} \rightarrow \mathrm{F}}$. The plot of the 
235 isomerizations of mannose to fructose, $\Delta H_{\mathrm{M} \rightarrow \mathrm{F}}$, and glucose to fructose, $\Delta H_{\mathrm{G} \rightarrow \mathrm{F}}$, were

236 calculated to be 18 and $24 \mathrm{~kJ} / \mathrm{mol}$, respectively. The positive enthalpies indicate that

237 both the isomerizations were endothermic reactions. Therefore, the yield of fructose

238 would increase with increasing temperature.

239 In conclusion, the isomerizations among glucose, mannose, and fructose were

240 significantly promoted in subcritical aqueous ethanol. Mannose and glucose were easily

241 isomerized to fructose. However, the isomerizations of fructose to glucose and mannose

242 and that between glucose and mannose were not favorable in subcritical aqueous

243 ethanol. Fructose mainly underwent decomposition when it was used as a substrate. The

244 kinetic study showed that $k_{\mathrm{M} \rightarrow \mathrm{F}}, k_{\mathrm{G} \rightarrow \mathrm{F}}$, and $k_{\mathrm{Fd}}$ were larger than the other rate constants.

245 Both the isomerizations of mannose to fructose and glucose to fructose had high

246 equilibrium constants, indicating that subcritical aqueous ethanol may be a useful

247 reaction medium to produce high fructose syrup. 


\section{Acknowledgement}

250 This work was partly supported by the Tojuro Iijima Foundation for Food Science and

251 Technology (D.G.) and by Japan Society for the Promotion of Science (Grant Number $252 \quad 26870296$; T. K.). 


\section{References}

254 [1] Bursać BN, Djordjevic AD, Vasiljević AD, Vojnović Milutinović DD, Veličković NA, Nestorović NM, Matić GM. Fructose consumption enhances glucocorticoid action in rat visceral adipose tissue. J. Nutr. Biochem. 2013;24:1166-1172.

[2] Akram M, Hamid A. Mini review on fructose metabolism. Obes. Res. Clin. Pract. 2013;7:e89-e94.

[3] Román-Leshkov Y, Chheda JN, Dumesic JA. Phase modifiers promote efficient production of hydroxymethylfurfural from fructose. Science 2006;30:1933-1937. derivatives using heterogeneous zeotype catalysts. Science 2010;328:602-605.

[5] EI Khaden HS, Ennifar S, Isbell HS. Contribution of the reaction pathways involved in the isomerization of monosaccharides by alkali. Carbohydr. Res. 1987;169:13-21.

[6] Tanase T, Takei T, Hidai M, Yano S. Substrate-dependent chemoselective aldose-aldose and aldose-ketose isomerizations of carbohydrates promoted by a combination of calcium ion and monoamines. Carbohydr. Res. 2001;333:303-312.

[7] Yanagihara R, Soeda K, Shiina S, Osanai S, Yoshikawa S. C-2 epimerization of aldoses by calcium ion in basic solutions. A simple system to transform D-glucose and D-xylose into D-mannose and D-lyxose. Bull. Chem. Soc. Jpn. 
[8] Moliner M, Román-Leshkov Y, Davis ME. Tin-containing zeolites are highly active catalysts for the isomerization of glucose in water. Proc. Natl. Acad. Sci. U.S.A. 2010;107:6164-6168.

[9] Kabyemela BM, Adschiri T, Malaluan RM, Arai K. Kinetics of glucose epimerization and decomposition in subcritical and supercritical water. Ind. Eng. Chem. Res. 1997;36:1552-1558.

[10] Usuki C, Kimura Y, Adachi S. Isomerization of hexoses in subcritical water. Food Sci. Technol. Res. 2007;13:205-209.

[11] Ellis AV, Wilson MA. Carbon exchange in hot alkaline degradation of glucose. J. Org. Chem. 2002;67:8469-8474.

[12] Vuorinen T, Sjöström E. Kinetics of alkali-catalyzed isomerization of D-glucose and D-fructose in ethanol-water solutions. Carbohydr. Res. 1982;108:23-29.

[13] Visuri K, Klibanov AM. Enzymatic production of high fructose corn syrup (HFCS) containing $55 \%$ fructose in aqueous ethanol. Biotechnol. Bioeng. 1987;30:917-920. employing thermophilic xylose isomerase in water-ethanol mixtures. Biotechnol. 
Lett. 1991;13:787-792.

[15] Angyal SJ. The composition and conformation of sugars in solution. Angew. Chem. Int. Ed. 1969;8:157-166.

[16] Gao D, Kobayashi T, Adachi S. Kinetics of sucrose hydrolysis in a subcritical water-ethanol mixture. J. Appl. Glycosci. 2014;61:9-13.

[17] Akiya N, Savage PE. Roles of water for chemical reaction in high-temperature water. Chem. Rev. 2002;102:2725-2750.

[18] Saravanamurugan S, Paniagua M, Melero JA, Riisager A. Efficient isomerization of glucose to fructose over zeolites in consecutive reactions in alcohol and aqueous media. J. Am. Chem. Soc. 2013;135:5246-5249.

[19] Topper YJ, Stetten DW. The alkali-catalyzed conversion of glucose into fructose and mannose. J. Biol. Chem. 1951;189:191-202. alkaline solutions. Carbohydr. Res. 1969;9:163-175. kinetics of monosaccharides in subcritical water. J. Food Eng. 2005;68:309-313. 
307 Scheme 1. Simplified reaction pathways for the isomerization of three hexoses in

308 subcritical aqueous ethanol.

309

310

311

312

313

314

315

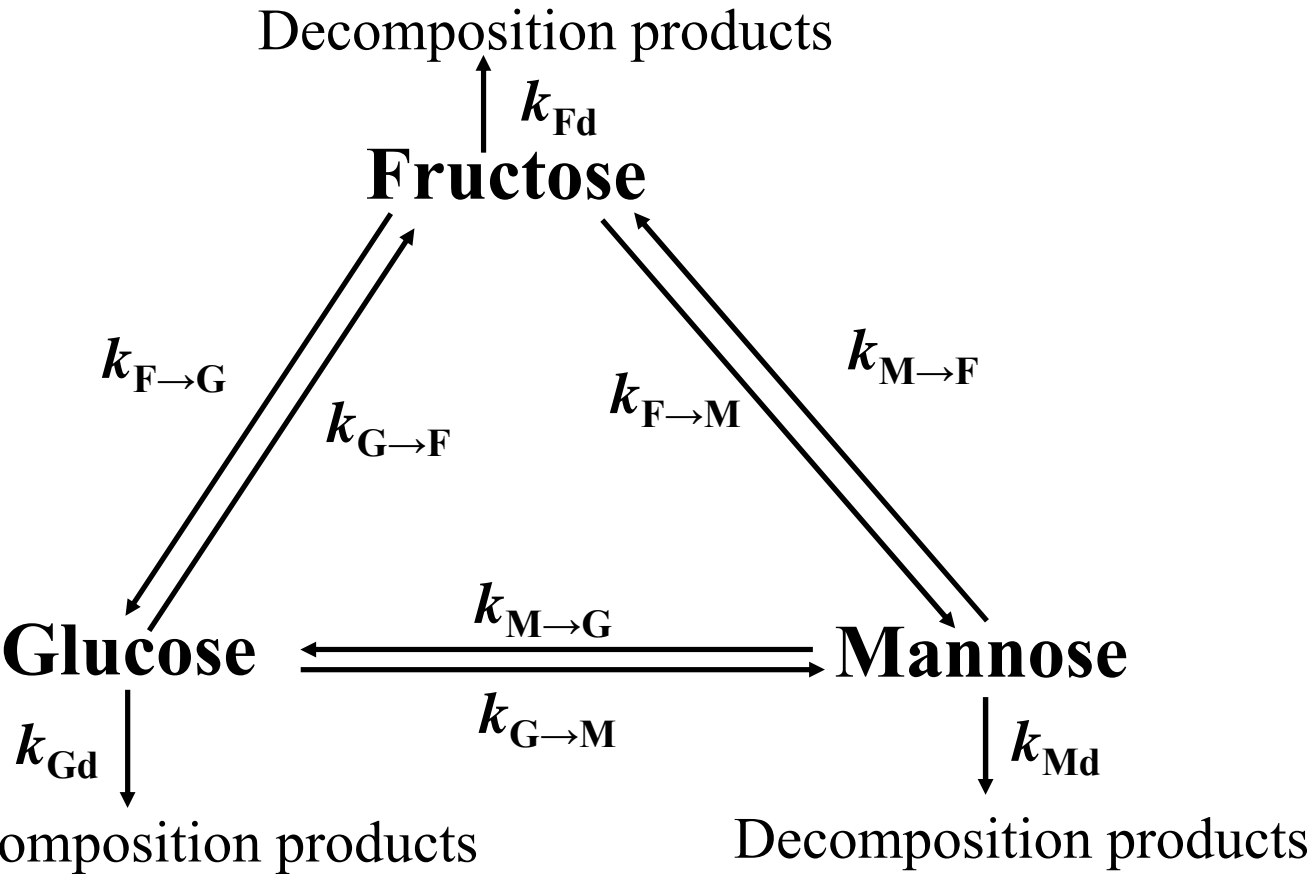

316

317 


\section{Figure Captions}

319

320

Fig. 1. Changes in (a) the fraction of remaining glucose treated at $180{ }^{\circ} \mathrm{C}$ in $(\triangle) 0 \%$

Fig. 2. Effect of ethanol concentration on the

fructose, $(\boldsymbol{\square}, \square)$ selectivity of mannose, and $(\boldsymbol{\Delta}, \triangle)$ the total saccharide content when glucose was treated at $180{ }^{\circ} \mathrm{C}$ (closed symbols) and $190{ }^{\circ} \mathrm{C}$ (open symbols) for $500 \mathrm{~s}$.

Fig. 3. Changes in (a) the fraction of remaining glucose at $(\bigcirc) 180{ }^{\circ} \mathrm{C},(\square) 190{ }^{\circ} \mathrm{C}$, and symbols) and mannose (closed symbols) obtained with residence times. The symbols in (b) are the same as those in (a). Curves show the calculated results.

Fig. 4. Changes in (a) the fractions of remaining $(\diamond)$ fructose, $(\square)$ glucose, and $(\triangle)$ 
mannose at $200{ }^{\circ} \mathrm{C}$ in $80 \%(\mathrm{v} / \mathrm{v})$ subcritical aqueous ethanol and (b) the yields of the

337 hexoses obtained with residence times. Symbols $\triangle$ and

$\Delta$ represent fructose and

338 glucose produced from mannose; $\square$ and $\boldsymbol{\square}$ represent fructose and mannose produced

339 from glucose; and $\diamond$ and $\diamond$ represent mannose and glucose produced from fructose,

340 respectively.

341

342 Fig. 5. Dependencies of the rate constants of the respective reaction steps on the ethanol

concentration at (a) $180{ }^{\circ} \mathrm{C}$, (b) $190{ }^{\circ} \mathrm{C}$, and (c) $200{ }^{\circ} \mathrm{C}$. The rate constants are expressed as follows:

$k_{\mathrm{M} \rightarrow \mathrm{F}},(\diamond) k_{\mathrm{Fd}},(\triangle) k_{\mathrm{G} \rightarrow \mathrm{F}}$

( $\mathbf{\Delta}) k_{\mathrm{Md}},(\bigcirc) k_{\mathrm{Gd}}$

(O) $k_{\mathrm{M} \rightarrow \mathrm{G}}$

$(\square) k_{\mathrm{F} \rightarrow \mathrm{M}},($

$k_{\mathrm{F} \rightarrow \mathrm{G}}$, and $(\boldsymbol{\nabla}) k_{\mathrm{G} \rightarrow \mathrm{M}}$.

Fig. 6. Arrhenius plot for the rate constants of the respective reaction steps in $80 \%(\mathrm{v} / \mathrm{v})$

subcritical aqueous ethanol. Symbols are the same as those shown in Fig. 5.

Fig. 7. Temperature dependence of the equilibrium constants for the isomerization of

mannose to fructose $\left(\square, K_{\text {eq, } \mathrm{M} \rightarrow \mathrm{F}}\right)$ and glucose to fructose $\left(\diamond, K_{\mathrm{eq}, \mathrm{G} \rightarrow \mathrm{F}}\right)$. 
357

358

359

360

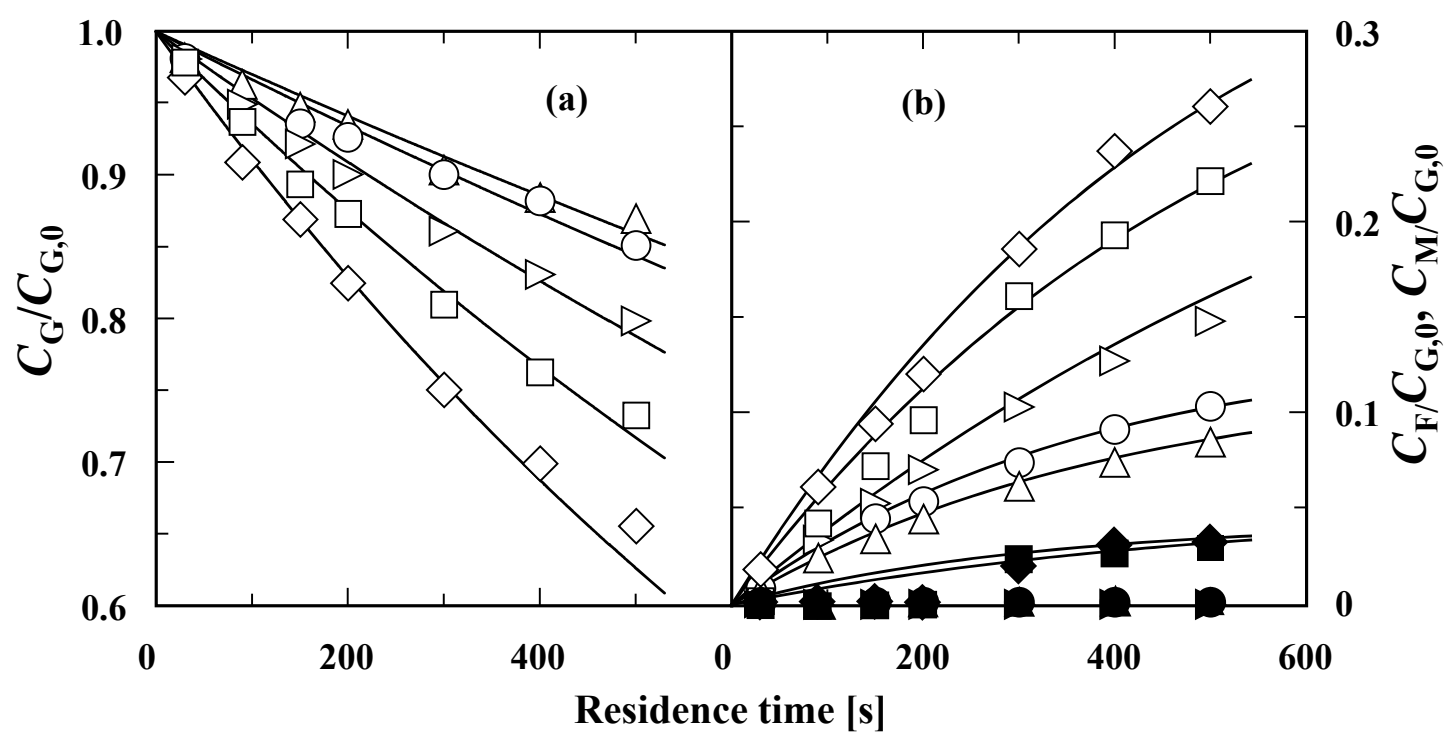

361

362

363

364

365

366

367

368

Fig. 1 Gao et al. 


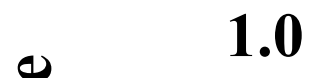

\section{3}

374

375

376

377

378

379

380
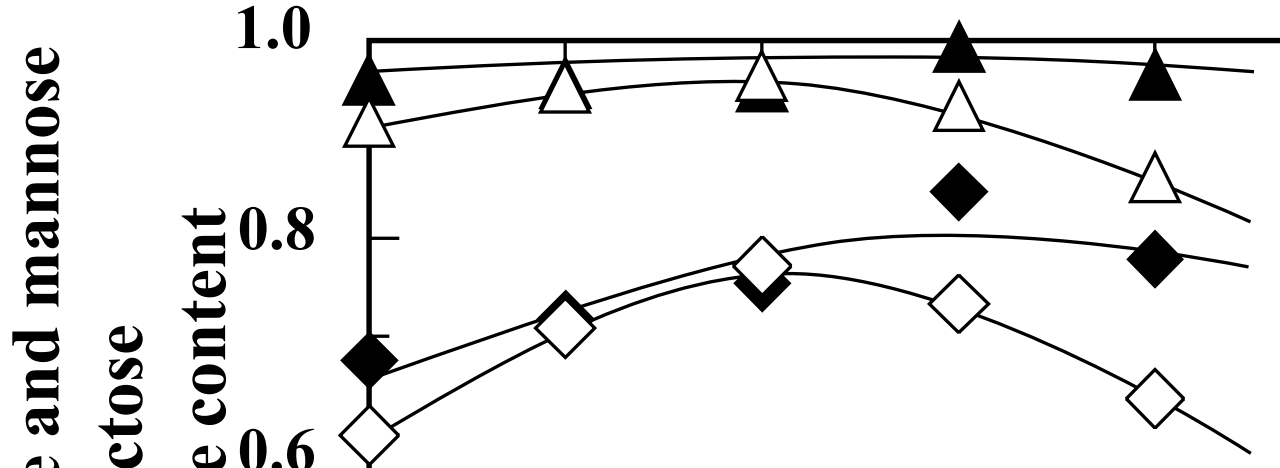

$\stackrel{8}{\circ}$

0.6

을

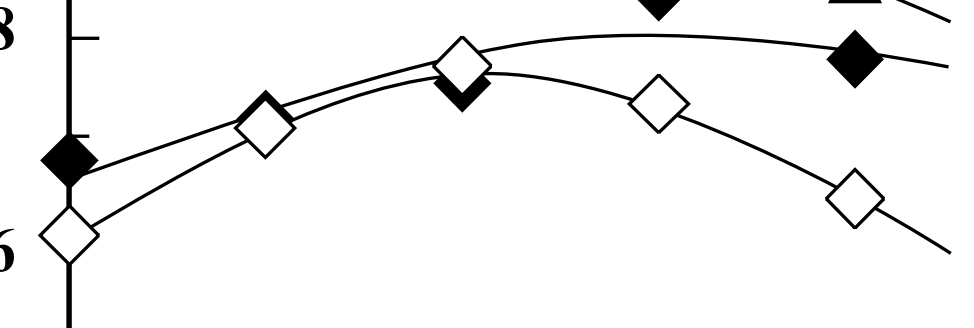

눙

$\frac{0}{0}$

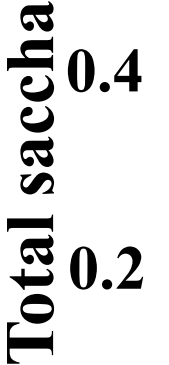

0

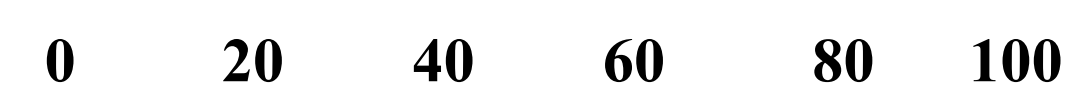

381

Concentration of ethanol $[\%, v / v]$

382

383

384

385

Fig. 2 Gao et al. 
390

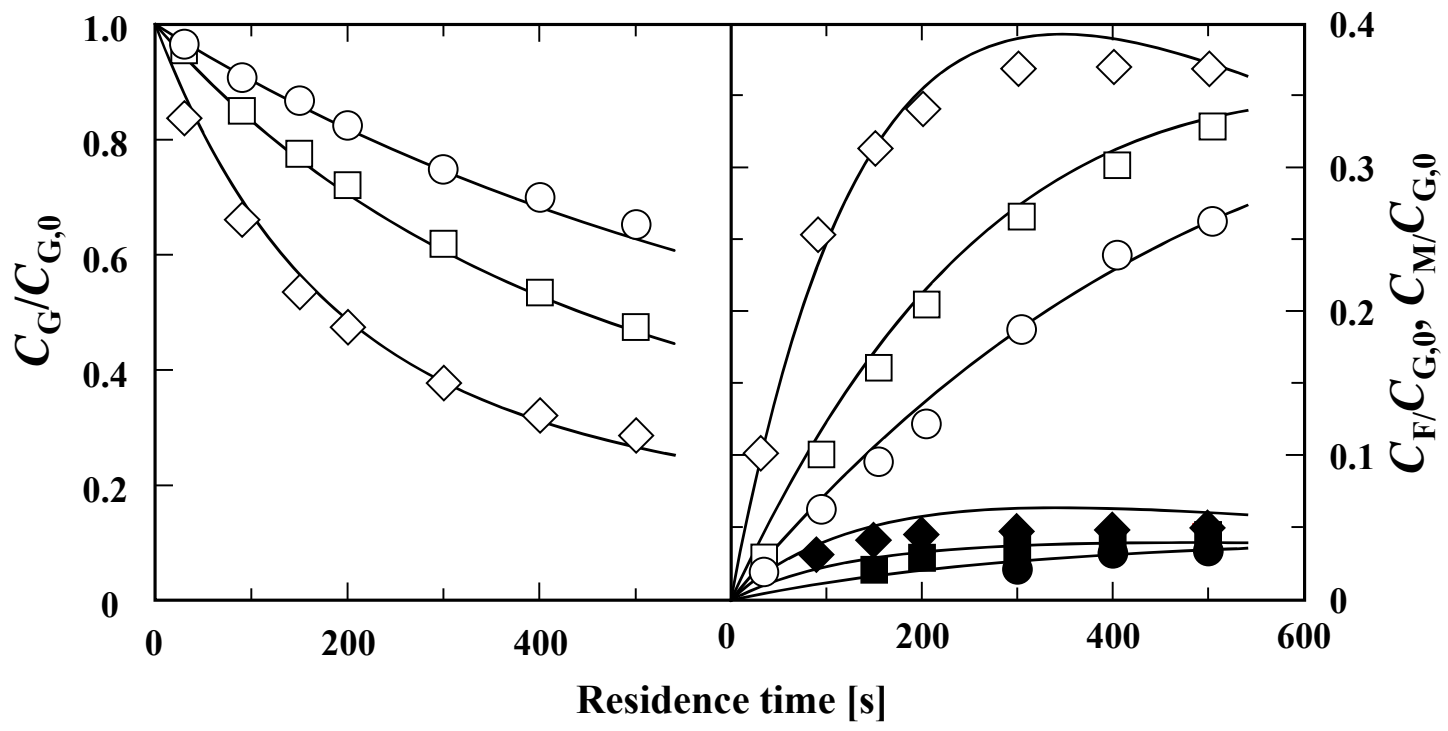

396

397

398

399

400

401

402

Fig. 3 Gao et al. 
407

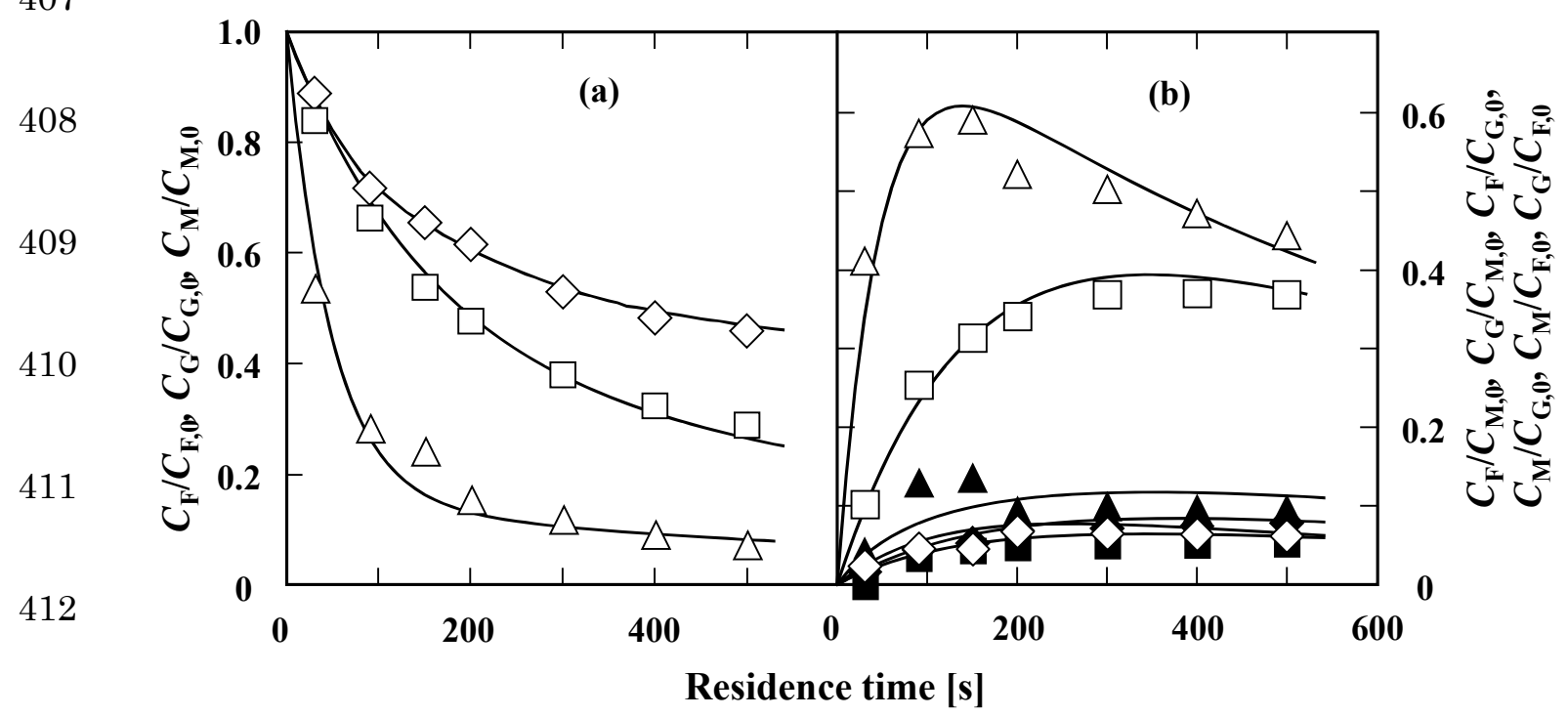

413

414

Fig. 4 Gao et al. 


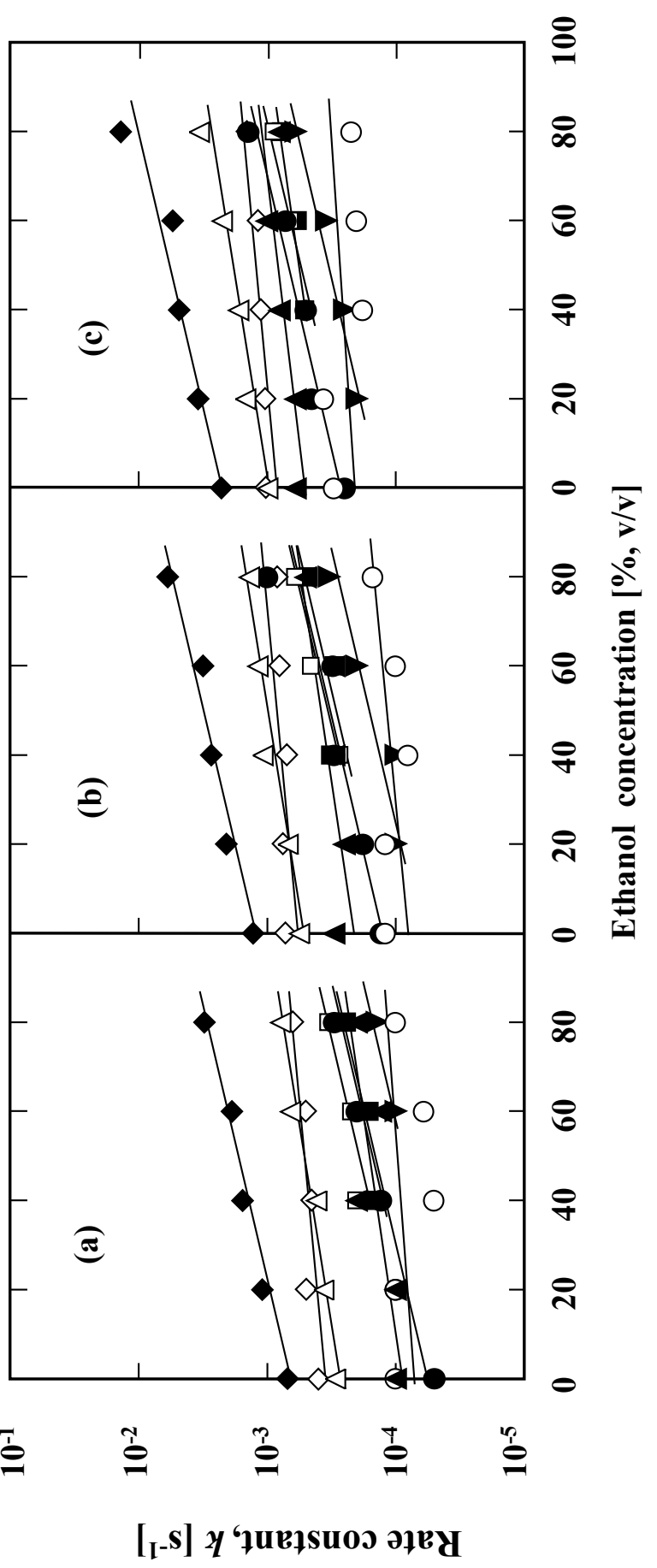

Fig. 5 Gao et al. 
Temperature $\left[{ }^{\circ} \mathrm{C}\right]$

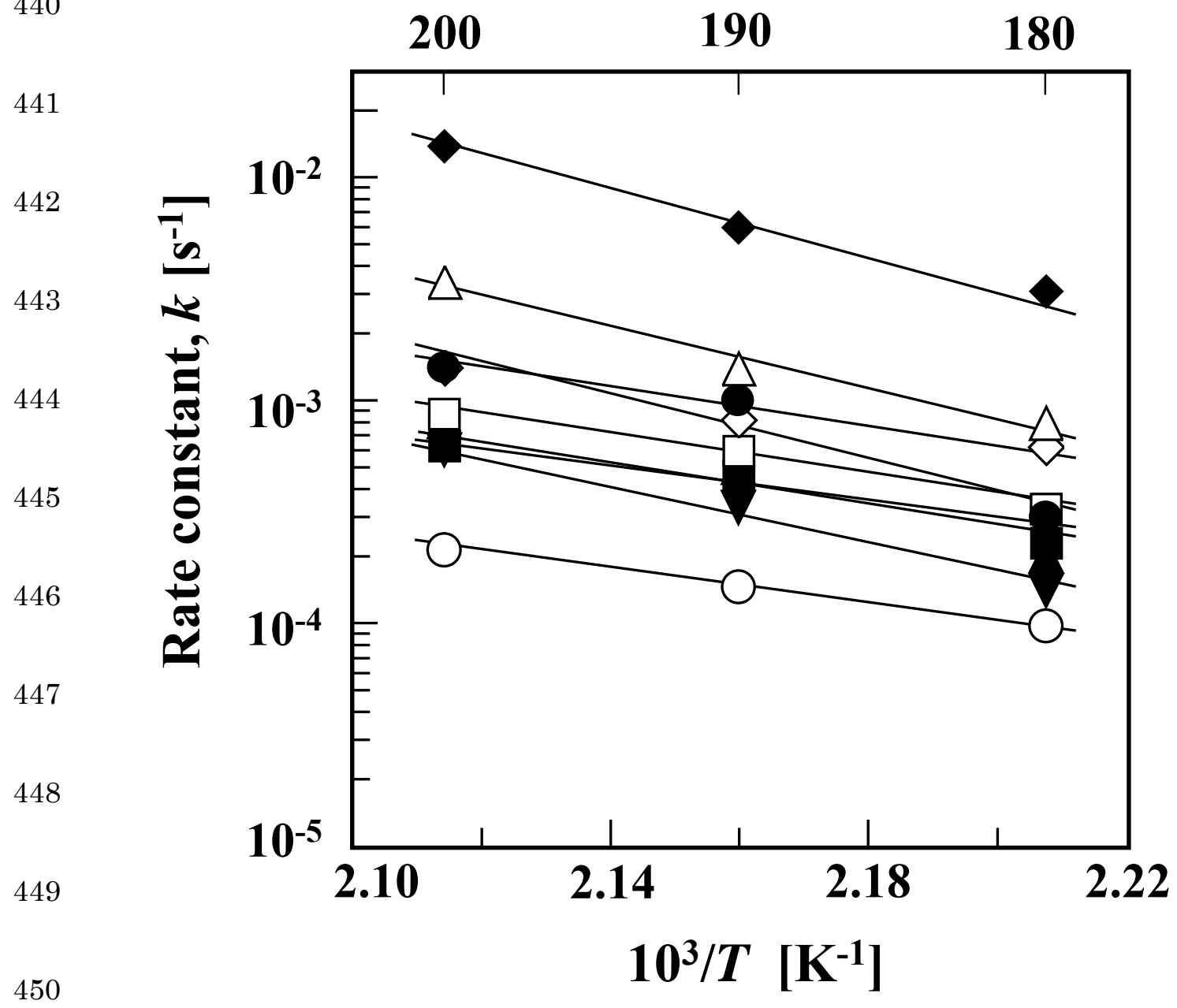

451

452

453

454 Fig. 6 Gao et al. 
Temperature $\left[{ }^{\circ} \mathrm{C}\right]$

458

459

460

461

462

463

464

465

466 200 190

180

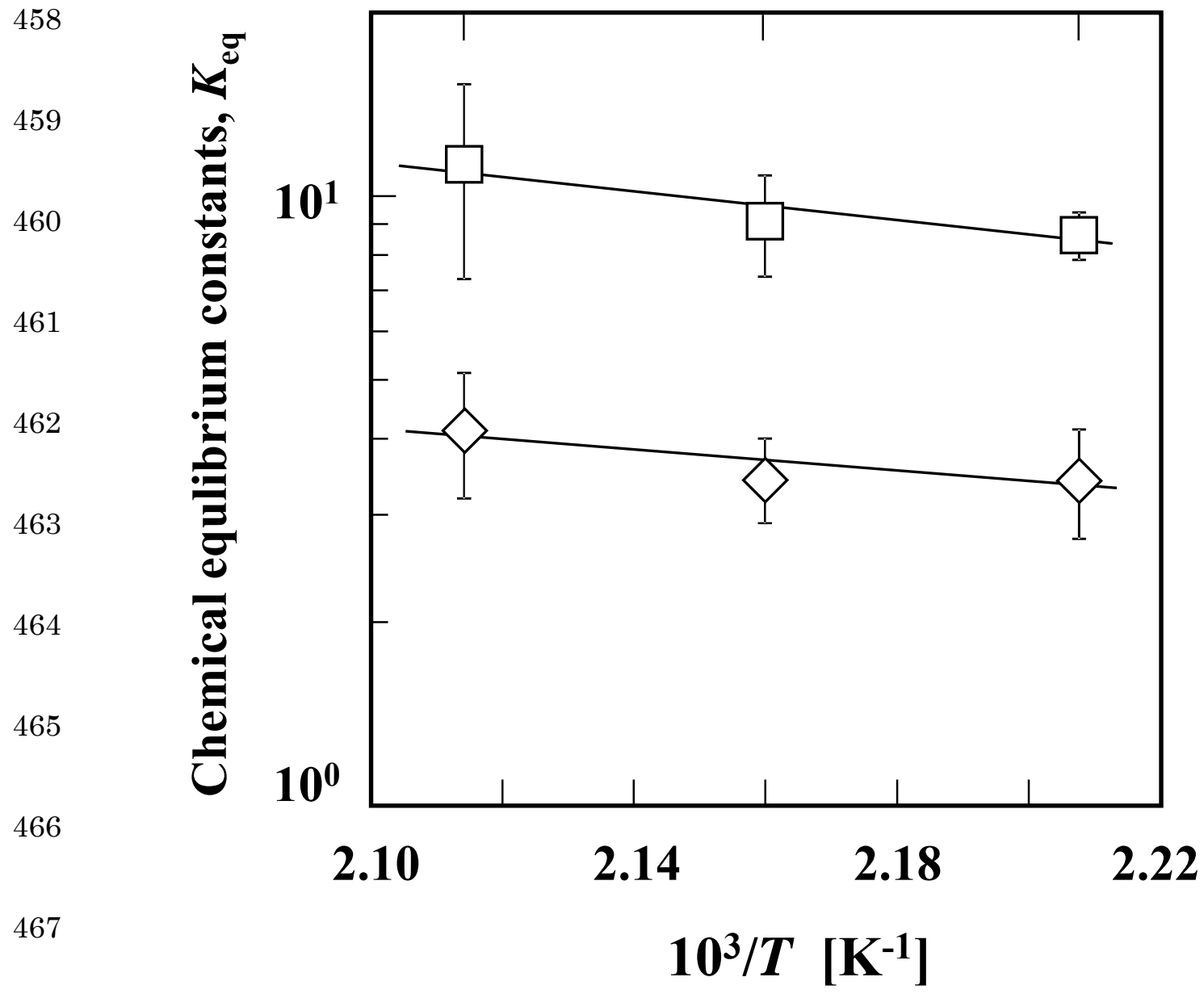

468

469

470

471 Fig. 7 Gao et al. 